\title{
A Close Look at the Matric Examinations in the Democratic Republic of Congo (DRC)
}

\author{
Matiki Talwanga
}

mtalwanga@cut.ac.za

\author{
Doi:10.5901/jesr.2015.v5n1p45
}

\section{Abstract}

Each country in the Southern African Development community(SADC) has its own educational system. The Democratic Republic of the Congo (DRC) which is one of the countries members of the SADC has its own. In this article we look into its educational system with the aim of checking some issues regarding the end of the high school Examinations and the certificate awarded to successful learners. These examinations are called "Examens d'Etat" The certificate awarded is called the "Diplome d' Etat" (State diploma). Some of the concerns we have brought forward on this article have been experienced for so long. It is in our opinion the right time that they require the closer look of the authorities to improve the situation. We compare the DRC's system to that of South Africa (RSA) with regards to this matter and suggest some recommendations.

\section{The Examens d'Etat}

In the month of June which coincides with the end of the academic year, learners in the Democratic Republic of Congo (DRC are required to seat for the end of secondary education exams. These exams are called "Examens d'Etat' (State exams). A successful learner to these Examen d'Etat is awarded a certificate called " Diplome d'Etat". This document opens doors to university studies and to some job opportunities. In this article we will use the following acronyms:

DRC for the Democratic Republic of Congo

EXETAT for Examens d'Etat (State exams).

DIPETAT for Diplome d'Etat (State diploma).

C.O. for cycle d'orientation (Orientation cycle)

In the next paragraph we wish to look at the duration of formal studies leading a student from his/her entry at primary school to the point of seating for the EXETAT.

\section{The Duration of Studies}

The DRC education system comprises of (1):

- Three years of nursery school,

Six years of primary school, followed by

- Six years of secondary school.

The secondary school which start with a two- years course known as Orientation cycle (Cycle d'orientation) is followed by a four-year cycle of high school called humanite's. It is here at the end of "Humanite's" that a learner is called to write the EXETAT.

In the next paragraph, we look into the curriculum learners in secondary follow which is the basis against which the EXETAT measure learner's performance..

\section{The High School Curriculum in the DRC}

During the Cycle d'orientation (CO), students are prepared and exposed to various fields from which learners choose an orientation he/she would have to pursue during his/her forthcoming 4 years of studies. The following options are available: Sciences(Marh-Physique, Biology-chemistry), commerce, pedagogique, literaire, social, technical(hospitality, dressmaking, mechanical, electricity, etc). The choosing of future courses of studies is guided by the learners 'own aspiration and by suggestions of the school's orientation committee based on the learner's academic performance.

There are four prescribed academic years of the humanities; the first two years of which are used for general studies in the chosen option of study. General concepts of Physics, chemistry, biology(micro-biology), economics and 
politics. The last two years of the humanite's cycle are devoted for specialization in the field through the teaching of core subjects unique for each particular option. During this period some other subjects(units) such as French, English, philosophy, geography, history, Religion, Education for life, are taught to all students regardless of options, to justify the nature of Humanite's(Humanistic approach).

Among the diverse options in the curriculum, we have chosen four to illustrate the kinds of core subjects and exams written per option as per the following table (3)

\begin{tabular}{|l|l|l|}
\hline Option & Core subjects written & Other subjects written \\
\hline Science(Math-Physique) & $\begin{array}{l}\text { Mathematics*, Biology*, physics, } \\
\text { Descriptive Geometry }\end{array}$ & $\begin{array}{l}\text { French, English, History, Geography, Philosophy, } \\
\text { Civic Education Aesthetic, microbiology, biology }\end{array}$ \\
\hline Science(Bio-Chemistry) & Biology*, Chemistry, Mathematics, Physics & $\begin{array}{l}\text { French, English, History, Geography, Philosophy, } \\
\text { Civic Education, Aesthetic, Micro-biology, Biology }\end{array}$ \\
\hline Literaire(Literature) & French*, Latin, Philosophy & $\begin{array}{l}\text { French, English, History, Geography, Civic Education, } \\
\text { Mathematics*,Micro-biology, Biology, Aesthetic... }\end{array}$ \\
\hline Commerce(administrative) & $\begin{array}{l}\text { Accounting(general and analytical), } \\
\text { Business Calculations, Law, Techniques } \\
\text { for Commerce, Typing and Shorthand }\end{array}$ & $\begin{array}{l}\text { Mathematics, French, English, Sociology, History, } \\
\text { Geography, Physics, Chemistry, Physical Education, } \\
\text { Civic education, Micro-biology, Biology, Aesthetic.... }\end{array}$ \\
\hline
\end{tabular}

Subjects marked with an $\left(^{*}\right)$ such as Mathematics and biology in the core section of math-physics and bio-chemistry according to the table differs in term of depths and extend of syllabus. Descriptive geometry, which is the basis of technical drawing is the link between mathematics and architecture.

\section{Concerning Security with Regard to the EXETATS}

The EXETATS are administered in centres which accommodate learners of schools surrounding each centre. Exam Centres are spread throughout the country and some centres are also established in the neighboring countries such as Angola, Rwanda, Burundi... to cater for learners of Congolese origin who are exiled in those countries. The administrative province of Kinshasa had 1,637 matric registered learners in 2013, which were accommodated in only 3 exam centres. The three exam centres were: Kinshasa East, Kinshasa Central and Kinshasa Ouest. In 2013 as many as 530,199 learners were registered to seat for the EXETAS throughout the country. There were 1,546 exam centres in the country (2).

The security around a centre is provided by members of the police force. Exams invigilators are also members of the police force as neither teachers nor any other member of the public is allowed to go closer to an exam centre. Members of the United Nations peace keeping forces (MUNESCO) deployed in the war- ravaged Eastern provinces of the DRC were called upon in 2013 to enforce security in and around exam centres of the North and South Kivu regions.(2)

Concerning the issue of security of the matric exams, the south African system is very relaxed yet effective. From 1995 to 2010 I was working as a mathematics teacher in a school in the rural area of the Eastern Cape province of South Africa. I was residing in town and my school was in a remote area. During the matric exam period, Each day before leaving town I would collect sealed envelopes containing exam papers from the educational district Office and would take them to the exam centre in my school (Impey Siwisa High School and later, Phandulwazi Agriculture High School). At the prescribed time, learners would converge to the centre. The envelope containing the exam papers would be inspected and opened to the satisfaction of the principal and students before the learners would be allowed to write the exam. Invigilators for each exam were members of the staff, teaching the grade 12 classes. The list of invigilators was known to the district. After the day's exam is over, I would be called to check the scripts and their number against the signed list of candidates. On my way back home to town I would submit these scripts to the exam section of the district office subjected to the same routine check. This level of trust towards a teacher has an empowering effect. One feels that his/her responsibilities being lifted to another level.

Weeks after matric exams are completely finished. Some selected teachers converge towards the exam marking centres where they will remain for a week or two for the marking process.

In one single year teachers are exposed to teaching, setting exams and now to marking matric exams. This activity brings a tremendous experience concerning handling matric classes. When this process is finished, the matric results are published. These results and their post mortem are released before the next academic year commences. This allows an informed grade 12 teacher to make timeous adjustments to his/her teaching goals and emphasis for the year ahead. 
This relaxed system is employed by the South African educational system. It is efficient and would surely be used for many years in the future.

\section{Features Observed on the Diplome d'Etat}

There are some security features on the DPETAT such as:

- The "DIPETAT" mentions the learner's name and displays the learner's photograph,

- The learner's date and place of birth, the option he/she was studying.

- On the right lower part there is the reference number of the DIPETAT, and the document is signed by the learner flanked by two members of the Examination board.

The document also mentions the total aggregate percentage of the units the learner wrote. For example refer to the copies of DIPETAT attached at the end of the article: section scientifique ; option Bio-Chimie $59 \%$ as it was the case for the author (Talwanga Matiki in 1977) and Mafuta Mubaya in 2009). As it can be seen clearly on these two copies, no major change has been done to the DIPETAT's features thirty-two years apart.

This document shows the option and section of the learner but fails to tell explicitly what units of the curriculum the learner has written, and most importantly it fails to display the marks obtained per unit of the exam written.

Compared to the South African matric statement of results, this DIPETAT is not self-explanatory and therefore causes a headache of figuring out its essence to the foreign university registration official.

I have been called many a time to explain to registration department the meaning of things such as section mathsphysique, pedagogique, commercial etc.. How can anyone know these concepts by mere looking at the DIPETAT as it is now and later credit the learner for courses he/she is not given proof of completion. At its present state, the DIPETAT attests completion of High School but does not tell the actual level of passing of the subjects which the registration Official needs to see in order to evaluate whether or not the learner meets the Faculty registration requirements.

For the colleges and universities in the DRC, this situation does not constitute a problem, since all administrators are native of DRC and have been brought through the system. But how many learners choose to study abroad?

Is it the responsibility of the learner or that of the examination board that tested the learner to inform the public of the details of the exams the holder of the "DIPETAT" has passed?

To make matter even more complicated, matriculant learners are given another document called the bulletin de "6eme secondaire". This document is carried by every high school graduate. Learners would attach it to the DIPETAT when they apply for admission at the University. This document is a record of marks for class tests and exams written by the learner during the first three quarters year prior to seating for the EXETAT, which are written during the last quarter of the academic year. As you would expect it, the percentage aggregate on the bulletin differs from the one on the Diplome d'Etat. Like the DIPETAT, the bulletin is not clear so as to put a demarcation between the two documents. There is no explanation regarding the marks it displays. It should at least say that these are the class tests marks, which are called Continuous Assessment marks (CASS marks) in South Africa.

There is no explanation concerning the way the marks on the bulletin affect those on the DIPETAT.

I have been asked several times to explain the disparity between marks on the Bulletin and marks on the DIPETAT and to write an undertaking letter stating that this is in practice in DRC .

We suggest that units written and marks obtained per each candidate be displayed on the DIPETAT. This will make the bulletin de sixieme secondaire redundant.

As mentioned previously, some non - examinable subjects have been dropped after the first semester to allow learners concentrate on the forthcoming exams. The subjects displayed on the Bulletin are not all written at the EXETAT. This again highlights and further stresses the fact that subjects written and the score to each individual subject must appear on the DIPETAT.

The examination board of the DRC does not tell learners which units they did well or those they did not perform well. As a result anyone who fails to get $50 \%$ aggregate in these exams has therefore failed the exams and has no other choice than repeating the year and subsequently rewriting all units of the exams the following year, even those subjects he/she might have passed. No supplementary exams are offered to learners. In DRC there are roughly half a million learners registered to seat for the EXETAT every year; It is recorded that candidates seat for the EXETAT in 2013. Because of war in some provinces of the country, learners from these affected areas have moved to and flooded schools of other provinces making it difficult if not impossible to get admission to school. Administrating the supplementary exams for failed subjects would turn to be a way forward to help learners and parents in this predicament. Many learners have resolved to suicide when no way forward seems possible. 
Does an aggregate percentage which is below $50 \%$ mean necessarily failure in all units of the option considered? Take for example two learners' marks for six subjects to be $51 \%, 41 \%, 45 \%, 40 \%, 58 \%, 50 \%$ and $80 \%, 46 \%, 45 \%, 47 \%$, $45 \%, 44 \%$ respectively. The aggregates percentages in this case are $47.5 \%$ and $51 \%$ respectively. Looking at these results, and based on the aggregates percentages only would anyone say objectively that the second learner has passed exams?

\section{Recommendations}

- Along with the security features on the Diplome d'Etat, the document should also display the subjects written and percentages obtained by the learner.

- The bulletin de 6eme secondaire should be used for early application and provisional admission to universities and Colleges. Since this is a report of the learner's continuous assessment marks and some practical exams marks prior to the EXETATs, then these results and those of the forthcoming EXETATS should be linked so as to give the learner one single document combining the CASS and EXETATS.

- The body of school inspectors should be empowered and should be more visible at school for monitoring the teaching and assessment. The number of inspectors should be equal to the task. In 22007-2008 academic year it is reported that there were 550 inspectors for 111,830 classrooms (1).The situation has not yet changed to the better in 2013. These inspectors should comprise of some for curriculum, some for matters concerning governance and some others for administrative and financial school matters. This will make senseless employing members of the police in academic matters while adding value to the teacher's profession.

- The supplementary examination should be administered to deserving learners.

- Each school should be made an exam centre. This prevents the feeling of disorientation and uneasiness experienced by learners when they have to travel to a centre far away from their usual place. This will solve the accommodation issue since the learners will not need to travel during the EXETATS period. During my time as a matric learner I had to travel to an exam centre located at a town $150 \mathrm{Km}$ from my school. During the one- week- long stay at that centre, the only accommodation we could get was a classroom without ablution. High school teachers should be encouraged to set matric exams questions. These questions collected from districts around the country should constitute the pool from which the matric exams questions are selected. We recommend that teachers be involved in processes of invigilation and marking the matric exams. This is a training ground for future school inspectors.

- The multiple choice type of questions/answers exam is not the best way of testing knowledge. The exam board should not use this as assessment tool. It promote cheating since a simple set of gestures agreed upon by learners can allow them communicate a lot of information. Besides, the multiple answers type of test does not permit a learner express him/herself. The procedure the learner employs to obtain an answer is equally important especially for subject such as mathematics.

- The South African model for management of Exam centres and marking centres has proved to be working well over the years. It should be emulated.

\section{References}

World Data on Education VII Ed. 2010/2011

Kongo times (22/04/2013 19:39)

Direction des programmes et materiel didactic, ESP-CEREDIP, Republique Dem du Congo 